\title{
"YOU ALL ARE SISTERS! WE ARE ALL FAMILY!" THE CONSTRUCTION OF PARENTHOOD IN RUPAUL'S DRAG RACE
}

\author{
DAVIDE PASSA \\ Sapienza University of Rome, Italy
}

\begin{abstract}
Drag queens epitomise gender fluidity, since they blur and parody the heteronormative male/female binarism. Their unconventional nature is reflected in the structure of their community, where they have created alternatives to the heteronormative family, which is historically based on heterosexual marriage and parenthood. Drag families are to be seen as places of personal and financial support, a refuge for young gay men who have been rejected by their "real" families and have financial problems. This study seeks to give prominence to the construction of parenthood in the reality television series RuPaul's Drag Race (2009-ongoing) by analysing the discourse - i.e. the system of statements around drag family, parenthood and sisterhood in a corpus of 174 episodes. The research is carried out in the light of Corpus Linguistics, with the use of \#LancsBox, a software programme for the analysis of language data and corpora.
\end{abstract}

Keywords: parenthood, drag queens, drag family, RuPaul's Drag Race, queer linguistics, corpus linguistics.

\section{INTRODUCTION}

RuPaul's Drag Race (2009-ongoing, henceforth $R P D R$ ) is a Netflix reality television series led by drag mother RuPaul Charles, in which a group of drag queens compete for the title of “America's Next Drag Superstar”. The show has become a popular phenomenon and RuPaul Charles - allegedly the most famous drag queen at the moment - has made drag culture much more accessible to 
global audiences. The series has had a fundamental role in propelling drag culture from the invisibility of the drag ball scene to the mainstream of reality television and hegemonic culture. Netflix made the series available almost everywhere in the world, and social networks are flooded with references to the show. It has been exported abroad with glocalised versions, such as Drag Race Thailand (2018-ongoing), The Switch Drag Race (Chile, 2015-ongoing), RuPaul's Drag Race UK (2019-ongoing), Drag Race Canada (2020-ongoing), Drag Race Down Under (Australia, 2020-ongoing), Drag Race España (2021ongoing), Drag Race Italia (2021-ongoing). RPDR and its glocalised versions show the mainstream audience the dynamics of 20th-century drag ball culture, where rival drag houses would compete for trophies and prizes. RPDR provides the viewers with an unconventional perspective of the family unit, which is not based on heterosexual marriage and parenthood, but on sorority and the construction of a "collective identity" where drag "sisters" can identify and support each other.

\section{Aim and methodology}

This article intends to investigate the construction of parenthood in $R P D R$ by analysing the discourse around drag family, parenthood and sisterhood in a corpus of 174 episodes (which will be referred to as the RPDR Corpus) including the English subtitles of all the thirteen seasons (to date) of the American show; the reference corpus that will be used is the spoken section of the Open American National Corpus (OANC Corpus, hereafter). The RPDR Corpus will be analysed using \#LancsBox (Brezina et al. 2021), a newgeneration software for the analysis of language data and corpora developed at Lancaster University. This research can be considered a corpus-based study, since it uses corpus data "in order to explore a theory or hypothesis, typically one established in the current literature, in order to validate it, refute it or refine it" (qtd. in McEnery and Hardie 6). The research will be carried out by analysing occurrences, relative frequencies (i.e. per 10k tokens), and collocations of node terms referring to the semantic field of drag parenthood and sisterhood (e.g. family, mother, sister, or daughter, among others).

In linguistics, the term discourse has a wide range of meanings, yet in this context it is to be understood as "a system of statements which constructs an object" (Parker 5) or, as Foucault puts it, as "practices which systematically form the objects of which they speak" (54). Burr maintains that discourse is "a set of meanings, metaphors, representations, images, stories, statements and so on that in some way together produce a particular version of events (...) surrounding any one object, event, person, etc” (32). These definitions imply 
that there are multiple discourses around the same object, reflecting the different attitudes that people have towards it. Along similar lines, there are multiple discourses around parenthood, and this article seeks to shed light on the one concerning drag queens. RPDR provides the viewers with an unconventional view of the family unit that is not based on heterosexual marriage and parenthood, but rather on "collective identity" (Way 1-80), a concept that will be developed in the following sections.

It should be borne in mind that $R P D R$ is a television show in which the mechanisms for the construction of parenthood might diverge from what occurs in real life. Moreover, the language that will be analysed in this study is a fictional reproduction of natural drag lingo, and every generalisation around drag lingo is to be made very carefully. Ferguson defines the study of fictional languages as 'ficto-linguistics' (1-17), that is the study of languages occurring not in society (as in socio-linguistics), but in fiction. Morevoer, Kozloff claims that fictional language diverges from natural language in that it "has been scripted, written and rewritten, censored, polished, rehearsed, and performed. Even when lines are improvised on set, they have been spoken by impersonators, judged, approved, and allowed to remain" (18). Moreover, the discursive construction of parenthood in RPDR might not correspond completely to real life, since what is being said and shown is mediated by the filter of television.

\section{DRAG QUEENS VS HETERONORMATIVITY}

Drag queens are not just men wearing female clothes and exaggerating female behaviours; they are mainly gay men - but not necessarily, since RPDR has hosted drag queens who are male-to-female transsexual people, as is the case of Peppermint (S9) - performing a parody of the heteronormative gender binarism. Oostrik maintains that drag queens' femininity is a performance of an exaggerated display of gender which ridicules restrictive sex roles and sexual identification (14). In Workin' It! (9), RuPaul states that "drag queens are essentially making fun of the roles people are playing, (...) and have become experts at parody, satire, and deconstructing social patterns". Drag queen Peppermint $(R P D R, S 9)$ claims that "the entire point of drag is to give the middle finger to rules of gender". Therefore, unlike transgender people, drag queens do not intend the performance of femininity sincerely, but as a critique towards the rigidity of heteronormative gender roles. Livia declares that there is a difference between transgender people and drag queens, since "a male-tofemale transsexual and a drag queen might use exactly the same stereotypical linguistic features which conventionally index femininity; but whereas the transsexual intends the performance of femininity sincerely and literally, the 
drag queen intends it ironically" ("The Future of Queer Linguistics” 92). However, it does not mean that transsexual people cannot perform as drag queens; Peppermint (S9) is one of the first drag queens who has openly declared her sexual transition. What changes is the intention behind gender performances, and drag queens have a sort of political stance against heteronormativity.

Cameron and Kulick define heteronormativity as "those structures, institutions, relations and actions that promote and produce heterosexuality as natural, self-evident, desirable, privileged and necessary" (55). This term was coined by Warner (3-17) and developed by Chambers and Nagel; the latter claims that heteronormativity is based on the "assumption that everyone is heterosexual and the recognition that all social institutions (...) are built around a heterosexual model of male/female social relations" (49-50). Heteronormativity implies that all human beings can be categorised within the binary system male/female, and that heterosexuality is the only acceptable sexuality, since only heterosexual intercourse leads - potentially - to procreation. Heteronormativity and all the institutions promoting it assume that sex and gender are aligned, and that all human beings are heterosexual. Western societies traditionally recognise only a two-gender system based on heterosexual men and women. This system of categorising people in just two exclusive groups is referred to as heteronormativity (Motschenbacher; Motschenbacher and Stegu). Marriage is one institution that has historically promoted heteronormativity in that it was only possible between a man and a woman, and should lead to procreation. Everything that falls outside the perceived heteronormative norms is considered a deviation, and dragqueenism is a socially-engaged art that satirises heteronormative social conventions. RuPaul's words, for instance, have a political echo, which is made explicit in S10E12:

RuPaul: Ladies, now, I once said every time I bat my false eyelashes, I'm making a political statement. (...) I want you to combine your Charisma, Uniqueness, Nerve and Talent ${ }^{1}$ for mother and country.

Drag queens are called 'ladies', and the seriousness of their political engagement is accompanied by a reference to false eyelashes, in line with the inversion of expected rhetorical routines, which is a typical feature of camp talk included in

\footnotetext{
${ }^{1}$ Note that the four qualities that a successful drag queen should have form the acronym C.U.N.T., which is itself a fierce critique towards heteronormativity. The explicitness of the expression used to refer to a serious matter is in line with paradox, a typical feature of camp talk defined by Harvey as "two apparently contradictory notions or views (...) held simultaneously, suggesting the possibility of a more inclusive and complex 'truth"”. (244)
} 
Harvey's macro-category of 'Inversion' (240-260), which involves the combination of two statements that should be in a causal relationship but are not, as the example above shows. Drag queens are the emblem of gender fluidity, according to which gender identities are not pre-existing attributes of an individual, but are created with the repeated actions that an individual performs (Butler 186-187). Gender fluidity is epitomised in drag queen Gigi Goode’s statement (S12E6):

Gigi Goode: I've kind of always teetered between male, female throughout my whole life. I think I really always carry some sense of female in me even when I'm in, you know, non-drag. Growing up, I've always been interested in feminine things. (...) I've kind of always thought there was no point to putting a label on anything in regards to gender. (...) I think I'm...fluid. Sometimes I identify as more male, and sometimes I identify as more feminine. And I think I'm both and I'm neither.

As Gigi Goode's statement shows, gender is "not a rigid or reified analytic category imposed on human experience, but a fluid one whose meaning emerges in specific social contexts as it is created and recreated through human actions" (Gerson and Peiss 317). Using Butler's words, "gender is the cultural meanings that the sexed body assumes; (...) what we take to be an internal essence of gender is manufactured through a sustained set of acts, posited through the gendered stylisation of the body" (9). To put it another way, unlike sex which is fixed unless one seeks help from surgery, "gender is a free-floating artifice" (Butler 10), it is performative, and language, behaviour, physical aspect, clothes, manners, etc. all play a significant role in this process. West and Zimmerman maintain that gender is not "what one is, but, more fundamentally, is what one does" (140).

\section{DRAG LINGO}

Drag lingo is an expression of the "umbrella" linguistic variety known as camp talk $^{2}$, which is characterised by the co-occurrence of linguistically contradictory features as a way to mock the heteronormative gender binarism. Barrett maintains that drag queens convey queerness "by skilfully switching between a number of linguistic styles and forms that stereotypically tend to denote other identities" (qtd. in Kulick 25). The lingo that drag queens have created reflects their gender fluidity and marginalised condition. Language is one of the means drag queens have at their disposal to create and perform their collective identity. They are members of a speech community, a group whose members are "in

\footnotetext{
${ }^{2}$ For a detailed description of camp talk, see Harvey 2000.
} 
habitual contact with each other by means of language, either by a common language or by shared ways of interpreting linguistic behaviour where different languages are in use in an area" (Swann et al. 293). The concept of speech community was first introduced by Saussure (92) and was developed by scholars like Lyons (1970), Hymes (1972), Labov (1972), or Sherzer (1977). Hymes summarises the different studies on speech community, defining it as

a community sharing knowledge of rules for the conduct and interpretation of speech. Such sharing comprises knowledge of at least one form of speech, and knowledge also of its patterns of use. Both conditions are necessary. (51)

Drag queens are members of a group based on a secret language, which creates a sense of drag "sorority" where they can identify and support each other. Kinship terms are very frequent, and gender inversion is particularly evident in this variety. Gender-crossing is a typical linguistic feature of gay male communities (Johnsen, “He's My Sister!”, “He’s a Big Old Girl!’” ; Livia, Pronoun Envy), involving the use of grammatical forms and female kinship terms (e.g. sister, mother, daughter, queen) to refer to gay men. Gender inversion consists in using female pronouns and adjectives to refer to men. Almost all the contestants in $R P D R$ are gay men; nevertheless, when referring to themselves and other drag queens, they tend to use the female grammatical gender, as shown in Table 1.

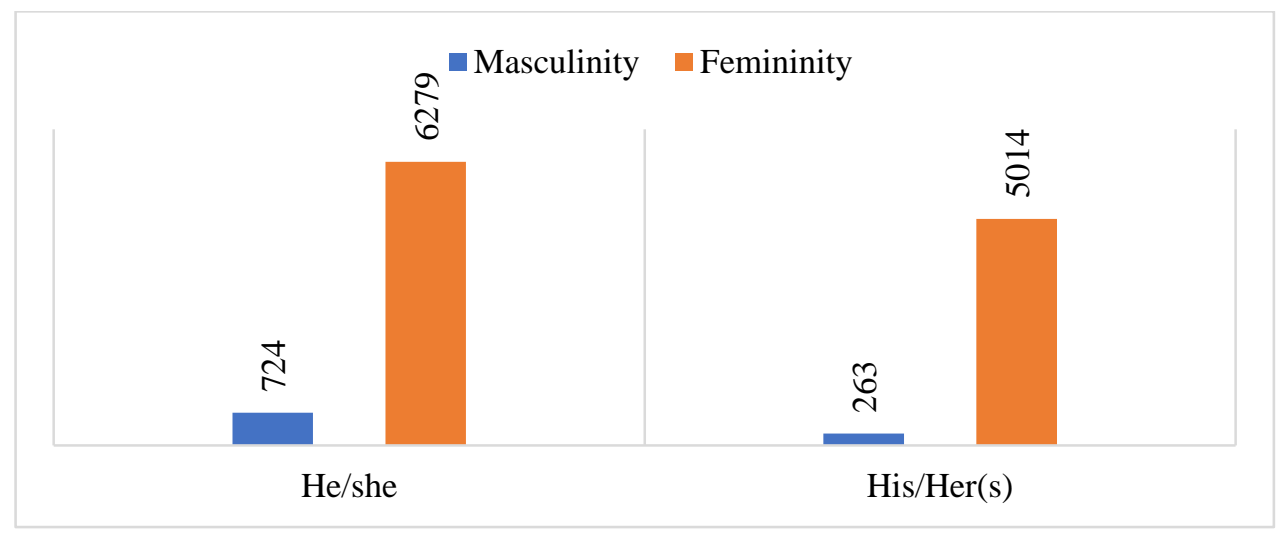

Table 1. Gender-crossing in RPDR Corpus

In $R P D R$, third-person singular pronouns and adjectives referring to women (i.e. she/her/hers) significantly outnumber those referring to men (i.e. he/his), which proves that masculinity is almost cancelled in the drag lingo portrayed in RPDR. The contestants use the female grammatical gender when they are both in and out of drag. Johnsen maintains that 
gender inversion seems to be most frequent in those gay subcultures where a conscious staging of gender is most apparent, for instance among drag queens (...). In these subcultures, gender inversion may convey an understanding of gender as a construction, as something we do, rather than something we are. (153)

Besides, drag queens might refer to themselves or close friends with terms such as sister/sis, to the person who first introduced them to gay society with the terms mother/mama/ma, and to a younger drag queen under their wing as their daughter. It should be borne in mind that, with the exception of female special guests and the judge Michelle Visage, $R P D R$ is a show made exclusively by men. Despite this, kinship terms commonly attached to women significantly outnumber those referring to men, as shown in Table 2.

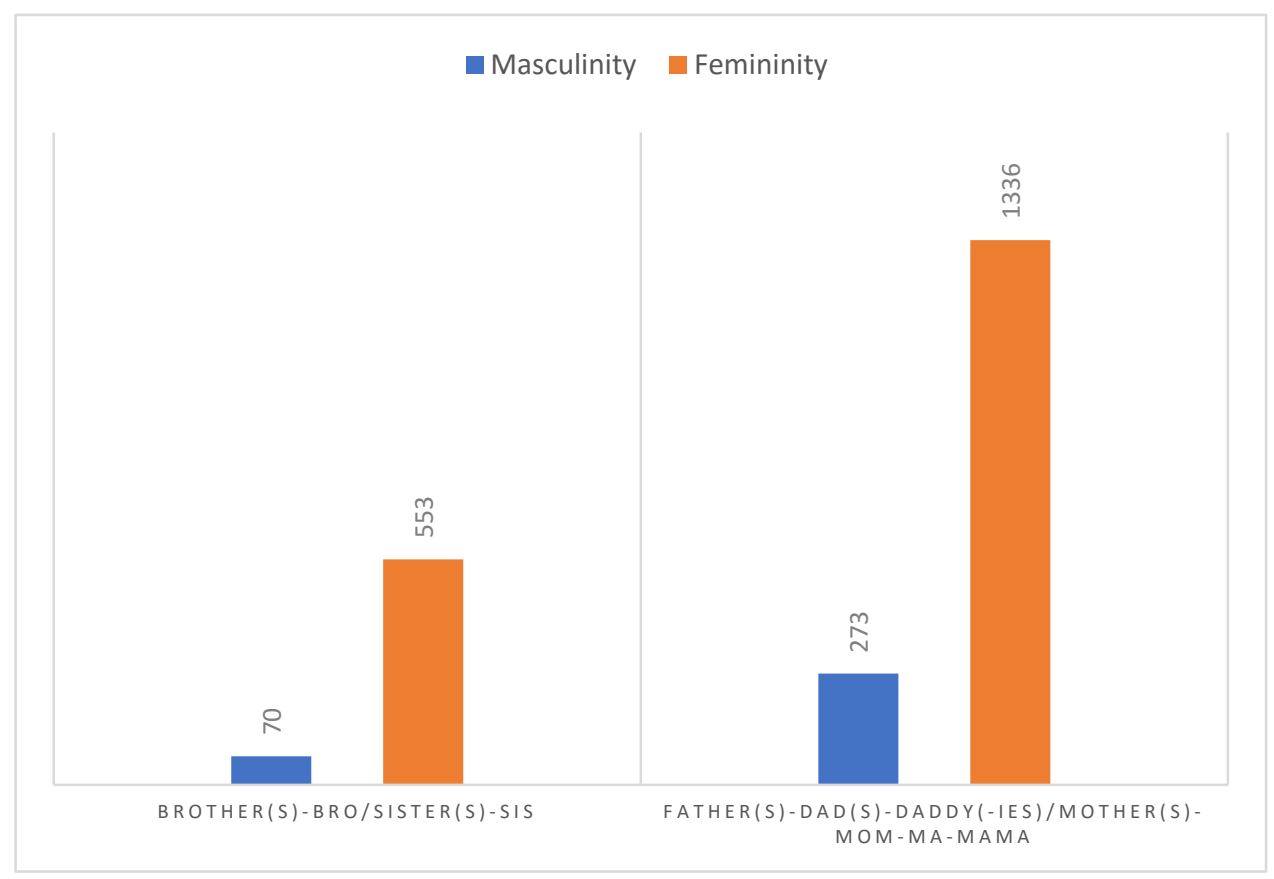

Table 2. Kinship terms in RPDR Corpus

The use of female kinship terms is consistent in the show, and it is a representative linguistic feature of drag lingo; hence the title of this study, which is inspired by Rupaul's declaration in S1E4, when she empathises with drag queen Ongina after she has revealed that she is HIV-positive: 
RuPaul: We all are sisters. We are all family. And if one of us is in pain, we are all in pain. We are all in trouble.

The recurrent use of first-person plural pronouns, as well as the use of kinship terms (i.e. sisters, family) helps construct a sense of belonging. Similarly, in S2E12 RuPaul maintains:

RuPaul: Look around you. These are your sisters. Win or lose, love or hate, we are family. And I am your mother.

Therefore, in $R P D R$, drag lingo is used to "destabilize and decouple univocal conceptions of biology, gender, sexuality, and alterity" (Moore 17). Grammatical gender-crossing transgresses the heteronormative gender binarism by suggesting that the contestants are both male and female, and that the boundary between the two genders is blurred.

The elimination of masculinity is also evident in the attitude that RuPaul and her daughters have towards male physical features, such as muscles, facial and body hair, which drag queens have to hide and feminise if they want to look 'real' ${ }^{3}$ and successful. Ongina (S1) was the first drag queen in the show who decided not to use wigs at all; her looks were completed by her natural, very short hair, which was often criticised by the judges, as in "I would've had your hair down, and just kicked up the femininity of your look a little bit more. (...) when I see you, I still see a little boy. I would love to see more of a little lady" (S1E5).

It follows that it is true that drag queens perform gender fluidity, but it is also true that there are certain basic rules that they need to adapt to in order to be successful; this was particularly true in the very first seasons of $R P D R$, when the contestants could only be biological men - in line with the traditional concept of drag queen - and perform particularly feminine drag characters; things have been changing throughout the years and in the last years $R P D R$ has become a much more inclusive show.

\section{RPDR FAMILY}

$R P D R$ reproduces (mutatis mutandis) the dynamics of the drag ball culture that was popular in Harlem (New York City) in the late 1960s, and which was based on balls where members of rival drag families would perform in various

\footnotetext{
${ }^{3}$ In drag lingo, the term 'real' stands for convincingly feminine.
} 
categories for prizes and trophies. Chauncey explains that "gay men created cultural institutions and rituals that fostered a sense of collective identity... the most prominent of these were the drag balls" (291). The ballroom phenomenon is the expression of a counterculture that began as an underground reaction to American heteronormative and homophobic culture, and has gradually become mainstream owing to audiovisual products such as Paris is Burning (1990), and the Netflix series RPDR (2009-2021) and Pose (2018-2021). The creation of drag families is to be seen as a reaction to heteronormative values according to which a man and a woman should marry and have children. Sokalska-Bennett has shown that the union of a mother and a father, who have produced children through heterosexual procreation, is central to the construction of the heteronormative family (61-89). As shown in Figure 1, which lists the words that collocate with the node term 'family', sorted into MI2 statistical order on the basis of the strength of collocation in the RPDR Corpus, the adjective 'drag' is one of the first lexical terms that collocates with the node 'family'. Moreover, the figure shows that the discourse around drag family in $R P D R$ is based on ideas which are aimed at creating a sense of belonging to the community: collocations such as 'family resemblance', which is used to emphasise the similarity of certain contestants' styles to their drag houses of origin, nouns such as 'member(s)', pronouns like 'we', and adjectives such as 'supportive' and 'chosen'. The adjective 'supportive' is used in the corpus mainly to compare the contestants' biological and drag families; the former tend not to support drag queens' lifestyle, whereas the latter are a shelter for drag queens who have been rejected by their real families. Drag queens share 'family values' because they are 'part' of the same, supportive community. Despite being a competition, $R P D R$ portrays a supportive community, as is underlined by RuPaul herself in S2E10:

RuPaul: Naturally there was some fierce competition between the queens. It's a competition. But what impressed me the most was the mutual love and support, because when it comes to drag, support is essential.

Reflections on the concept of support and the contestants' gratitude for receiving it are very much reiterated in $R P D R$. Tender moments, when the contestants reveal their fragility with moving words, are often exploited in the show to remember that drag community is a place where drag queens receive emotional support. This is also evident in the dialogues where the term 'support' appears, in that the word is hardly ever used in a financial sense; it is rather used to refer to psychological and emotional assistance that drag sisters give to each other. 


\begin{tabular}{|c|c|c|c|c|c|c|}
\hline Index & Status & Position & Collocate & $\nabla$ Stat & Freq (coll.) & Freq (corpus) \\
\hline 1 & 。 & R & resemblance & $17.4949865 \ldots$ & 49 & 56 \\
\hline 2 & $\circ$ & $R$ & values & $13.6578956 \ldots$ & 6 & 12 \\
\hline 3 & 0 & $L$ & members & 12.6578843. & 6 & 24 \\
\hline 4 & 0 & $R$ & drags & $12.2573494 \ldots$ & 5 & 22 \\
\hline 5 & $\circ$ & $L$ & member & 12.1553819. & 6 & 34 \\
\hline 6 & 0 & $R$ & supportive & 12.1553819... & 6 & 34 \\
\hline 7 & 0 & $\mathrm{~L}$ & my & $11.9786182 \ldots$ & 106 & 11995 \\
\hline 8 & 0 & L & strong & $11.8698958 .$. & 15 & 259 \\
\hline 9 & 0 & $L$ & drag & 11.3011478. & 53 & 4796 \\
\hline 10 & 0 & L & chosen & $11.2428468 .$. & 6 & 64 \\
\hline 11 & 0 & L & $a$ & $11.0448037 \ldots$ & 111 & 25127 \\
\hline 12 & 0 & L & your & $10.9660076 \ldots$ & 65 & 9100 \\
\hline 13 & $\circ$ & L & modern & $10.9354213 .$. & 5 & 55 \\
\hline 14 & 0 & L & part & $10.8587979 \ldots$ & 15 & 522 \\
\hline 15 & 0 & $L$ & we & $10.7282661 \ldots$ & 46 & 5374 \\
\hline
\end{tabular}

Figure 1. Search Term: family; Statistic: 04 - MI2; Span: 5-5; Collocation freq. threshold: 5.0; Statistic value threshold: 6.0 .

Drag families are also known as drag houses, that is, "larger kinship units that offer a support nexus for female impersonators and present opportunities for strong interpersonal relationships to be forged" (Schacht and Underwood 145). Drag families are based on a rigid hierarchy, at the top of which there is a drag mother - the most influential drag queen in the house - who has experience and is a mentor to her drag daughters, who are less popular (and usually, but not necessarily, younger) drag queens. Drag daughters commonly refer to each other as drag sisters, as was mentioned in the previous section. According to Way

drag sister is the most liberal term in defining relationships between queens, because in contemporary drag culture queens refer to each other as drag sisters at times even when they are not members of the same house. Drag sister is more of a general term of respect that bonds queens together based on their collective identity. (4)

Therefore, no matter what drag family a drag queen belongs to, she will still be considered a drag sister by the members of her rival houses, unless there is some specific friction as in every human relationship. In the opening of the Grand Finale (S10E14), RuPaul addresses all the "girls" by saying

RuPaul: Here in the House of RuPaul everybody is welcome. There ain't no walls here to divide us. There's only love, and now let's say it loud enough so they could hear it in Washington D.C. Everybody say love!

Her statement shows that the ideas of sisterhood and family are much more inclusive among drag queens; even though drag families are in competition with 
each other during drag balls, the boundaries of drag houses are much more blurred than in "biological" families, since everyone can join a drag house and be called "sister". Drag mothers save their drag "daughters", providing personal and financial support. They teach their daughters how to make-up, sew their clothes, lip-sync, dance and other performative skills. The more trophies a house wins, the more popular it becomes. According to Moncrieff and Lienard, the competition between drag queens facilitates the emergence of hierarchy within drag families, where drag mothers are at the top and their daughters can benefit from their mothers' elevated social status (10). Legendary houses, very often mentioned in RPDR and taken as models, are the House of Ebony, the House of Xtravaganza, the House of LaBeija, the House of Balenciaga. As members of a family, drag queens adopt the name of the house they belong to as their last name, that is their drag mother's name; this is also reminiscent of fashion houses (e.g. House of Gucci, House of Chanel, etc.), and is a further element differentiating drag families from heteronormative families, where children usually - but not necessarily - adopt their father's last name, although in some societies people adopt both parents' surnames or, in the absence of the father or for other legal reasons, their mother's name.

Therefore, economic issues, success, "a universal disposition for status seeking” (Moncrieff and Lienard 10) and emotional support are at the basis of the construction of family ties among drag queens. Since few paid professional opportunities are available for individual drag queens (Hopkins 135-149), the struggle facilitates the creation of drag families, which support the new members economically, as is evident in Tyra's (S2E12) words after joining the House of RuPaul:

Tyra: Before I came here, I didn't have a place to stay. I was sleeping on my drag mother's floor. I didn't have a job. When I came here, my goal was to win. If I went home empty-handed, like, that wasn't an option.

However, according to Hopkins, joining a drag family has both advantages and disadvantages for young performers' careers (145-146). They can take advantage of their mothers' skills, visibility and financial support, but this hierarchical system can sometimes prevent younger drag queens from developing their independence. It is common that drag daughters seeking their autonomy decide to leave their drag families to create their own drag house, which, in the spirit of the competitive drag ball room culture, will inevitably lead to rivalry.

Nevertheless, it should be borne in mind that $R P D R$ is a television product, and that the construction of the discourse around emotional rather than financial support is more audience-friendly, in that through emotional scenes the 
audience can empathise with the contestants. Most of the 67 occurrences of the term 'support', indeed, are used in an emotional context, usually after a tearjerking scene. References to financial support are significantly fewer, often limited to when RuPaul lists the prizes that the winners of the challenges get, or when references are made to the economic difficulties that the contestants had to face in their past. The predominance of an emotional discourse is confirmed by the data obtained with the software programme: the entry term 'love' figures as one the positive keywords - i.e. words that are unexpectedly more frequent in the corpus under scrutiny than in the reference corpus - in that it has a relative frequency of 18,74 in the RPDR Corpus and 4,99 in OANC Corpus; similarly, the entry term 'money', which makes reference to the financial aspect of drag support, figures as one of the negative keywords - i.e. words that occur unexpectedly less in the RPDR Corpus than in OANC Corpus- in that it has a relative frequency of 1,84 in the corpus under scrutiny and 2,93 in the reference corpus.

The predominance of an emotional discourse is also due to the fact that, historically, members of drag houses belong to social minorities for both their sexuality and ethnicity; they are very often rejected by their families of origin and, in response to that, choose to create their own families, or become members of an already established one, to seek emotional and psychological support. In the preface to the British play Wig Out!, Tarell Alvin McCraney maintains that

drag houses can be like the home you never had or the home you never wanted. It's the bond of the house that makes people family, but - just like family - they can be dysfunctional. More often than not, the people coming to join a drag house are already hurt and scared from their own homes, and they bring those wound into their new family. (5)

In Paris is Burning (1990), which is a kind of "essay in images that introduces us to the drag world and drag performances" (Ferrante 155), as well as a source of inspiration for RPDR, drag queen Pepper LaBeija maintains that

when someone has rejection from their family, when they get out in the world, they search someone to fill that void. (...) I've had kids come to me and latch hold to me like I'm their mother or like I'm their father. Houses are not parodies, or grotesque impressions: they are ties among real people, mutual ties built through voluntary affiliation.

Throughout $R P D R$, it is very common that the contestants show their pain due to familial abandonment or non-acceptance. As Metzger maintains, "although these stories work to evoke audience empathy, they also reaffirm neoliberal values of 
individualism" (50) and self-sufficiency. As a matter of fact, tender moments in $R P D R$ are often followed either by successful performances or by the reaffirmation of one's strength and individuality. They are also followed by explicit statements of what being part of a drag family means, as a way to highlight the supportive nature of drag houses. These dynamics are epitomised in the dialogue between RuPaul and Roxxxy Andrews, just after her elimination from the show (S5E7):

Roxxxy Andrews: It just hits me like not feeling wanted enough, not being good enough, I just feel like my mom never wanted me. (...) I come out as a strong character, I've tried to stay so strong, but I'm weak. It just hurts that I was left. Nobody cared.

RuPaul: We. Love. You. And you are so welcomed here. You know, we as gay people, we get to choose our family. We get to choose the people we're around. You know what I'm saying? I am your family, we are family here. I love you. I love you.

Roxxxy Andrews's dejection after her elimination brings to her memory the rejection she had from her biological mother. She feels unwanted from both her real mother and her drag mother. RuPaul replies using the first-person plural forms "we" and "our" and reinforcing the sense of belonging by calling her group a "family". She adds that, as queer ${ }^{4}$ people, they have the opportunity to choose the family they want to belong to if their real families do not accept their sexuality. Drag family is a chosen family, in opposition to one's biological family, which cannot be chosen. In S5E14, RuPaul reiterates

RuPaul: You (Roxxxy) are my child now. We, as gay people, we get to choose the families. We create families on our own on this journey, and all of my girls, you, all of the girls on this stage and the girls in the audience, we are one big, happy family, and we will all be there for one another.

Similarly to Roxxxy, Jujubee (S2E9) reveals to Raven (S2) that she was abandoned by her biological mother, and she thanks her drag mother Charisma Jeneva Jackson Taye for having accepted her as her drag daughter; she goes even further, in that she calls "mother" her drag mother Charisma Jeneva Jackson Taye, without differentiating the latter from her biological parent:

Raven: Do you talk to your drag mother more than you real mother?

Jujubee: I don't talk to my real mother at all. (...) She abandoned me. My father died when I was 15. Six months later, my mother found somebody else, and she

\footnotetext{
${ }^{4}$ The term "queer" is used here to refer to all non-heterosexual people, as a much more inclusive concept than the acronym LGBTQ+.
} 
left me to take care of my two younger sisters and to just grow up by myself, and I just stopped being a kid. I just want to thank my mother, Charisma Jeneva Jackson Taye.

Nonetheless, drag families are not to be seen as a mere refuge from deteriorated familial ties. It is very common among drag queens joining $R P D R$ to have lost one of or both their parents; the loss makes them more sensitive to relationships, as shown by Asia O’Hara (S10E4) when she told the other contestants about the loss of her parents:

Asia O’Hara: I was 27 when my parents passed. (...) You don't know what being alone feels like until you don't have a family connection. (...) Doing drag gave me those family connections. That's why I really kind of take these moments to heart, because I don't know when I'm gonna see y'all again after this.

In S10E10 she adds that:

Asia O'Hara: There's something that happens when you lose your parents at an early age. (...) I think that the beauty that came out of that for me was I became hyper-sensitive to family connection with people that I'm not related to.

RuPaul: So you're creating family outside of your blood family.

Nevertheless, drag queens' biological families can also be supportive up to a point where one's real mother and drag mother coincide. This is evident in Gigi Goode's (S12E1) words, which surprise the other contestants:

Others: I am living for this outfit of yours.

Gigi Goode: Thank you. My mother made it.

Others: Birth mother or drag mother?

Gigi Goode: Both.

Others: Your mom is your drag mom?

Gigi Goode: Technically, yeah. She's a theatrical costume designer...

It should be said that this is an exception, since most of the contestants complain about the fact that they have not been supported by their biological families, and that revealing their drag nature to their parents has been considered a second coming out, even harder to accept. 


\section{CONCLUSIONS}

Drag families, which are also known as drag houses, are based on a strong hierarchical order, being led by a drag mother who chooses to take under her wing less experienced drag daughters. Drag families are presented as based on mutual love and support among their members; they are social places where aspiring performers can find consolation and learn the drag art. This article has sought to explore the construction of a non-heteronormative type of parenthood among drag queens in the Netflix series $R P D R$. For the first time and with a considerable success all over the world, the series brings the dynamics of the drag ballroom culture to the attention of the mainstream audience. References to drag families are constantly made throughout the seasons and the language used to label family roles reflects their gender fluidity and contradictions. For this reason, the first part of this study has sought to define who drag queens are and what genderlect they use. Drag lingo is only one means, though a fundamental one, that drag queens have at their disposal in the process of creating and performing their collective identity and gender subversion.

The analysis of the RPDR Corpus shows that femininity has a strong impact on drag lingo, both in grammatical forms and kinship lexicon. The occurrences of female forms outnumber their male counterparts by far. From the analysis of the RPDR Corpus, it also emerges that the discourse on drag family in $R P D R$ revolves mainly around emotional support, even though references are also made to the financial support that drag queens get within drag houses. It is precisely the struggle to make drag art into a job that facilitates the emergence of drag families (Hopkins 135-149). The drag queens in the show make reference to the straitened circumstances they used to live in before joining the House of RuPaul. However, as the data discussed above have proved, RPDR focuses mainly on the emotive (rather than financial) aspect of drag families, which is more suitable to television. Tender moments are common in every episode, which is a way to make the audience know and empathise with the contestants. Drag queens have often passed through a difficult time in their life, and the consolation they find in their drag family is fundamental for their rebirth and success. The drag queens in the show wish for emotional support because of among other things - the deteriorated ties with their biological families, which led to familial abandonment or non-acceptance. Besides, drag families are also seen as a shelter for orphan drag queens, who lost one of or both their parents. Language, physical look, and the construction of an alternative parenthood are all forms of appropriation of the symbols of heteronormative domination, which are used by drag queens as a means of resisting the domination itself (Barrett 163). 


\section{Works Cited}

Barrett, Rusty. "Supermodels of the World, Unite! Political Economy and the Language of Performance Among African American Drag Queens.” The Language and Sexuality Reader, edited by Cameron, Deborah and Kulick, Don. London, New York: Routledge, 2006, pp.151-163.

Barrett, Rusty. "Supermodels of the World Unite! Political Economy and the Language of Performance among African-American Drag Queens.” Beyond the Lavender Lexicon: Authenticity, Imagination, and Appropriation in Lesbian and Gay Languages, edited by Leap, William L. Buffalo, New York: Gordon and Breach, 1995, pp. 207-226.

Brezina, Vaclav et al.: \#LancsBox v. 6. (software). Available at: http://corpora.lancs.ac.uk/lancsbox. (21.08.2021).

Burr, Vivien. An Introduction to Social Constructionism. London, New York: Routledge, 1995.

Butler, Judith. Gender Trouble. Feminism and the Subversion of Identity. Taylor \& Francis, 1990.

Cameron, Deborah and Kulick, Don. Language and Sexuality. Cambridge: Cambridge University Press, 2003.

Chambers, Samuel. "Telepistemology of the Closet; or, The Queer Politics of Six Feet Under.” Journal of American Culture, vol. 26, no.1, 2003, pp. 24-41.

Chauncey, George. Gay New York. Gender, Urban Culture, and the Making of the Gay Male World, 1890-1940. Basic Books, 1995.

Ferguson, Susan. L. "Drawing Fictional Lines: Dialect and Narrative in the Victorian Novel.” Style 2, 1998, pp. 1-17.

Ferrante, Anna Antonia. "Super Troopers: The Homonormative Regime of Visibility in RuPaul's Drag Race.” RuPaul's Drag Race and the Shifting Visibility of Drag Culture, edited by Brennan, Niall and Gudelunas, David. Palgrave Macmillan, 2017, pp. 153-166.

Foucault, Michel. The Archeology of Knowledge. London: Tavistock, 1972.

Gerson, J. and Peiss, K. "Boundaries, Negotiation, Consciousness: Reconceptualizing Gender Relations.” Social Problems, vol. 32, no.4, pp. 317-331.

Harvey, Keith. "Describing Camp Talk: Language/Pragmatics/Politics.” Language and Literature, vol. 9, no.3, 2000, pp. 240-260.

Hopkins, Steven. J. “Let the Drag Race Begin.” Journal of Homosexuality, vol. 46, no. 3-4, 2004, pp. 135-149.

Hymes, Dell. "Models of the Interaction of Language and Social Life.” Directions in Sociolinguistics: The Ethnography of Communication, edited by Gumperz, John and Hymes, Dell. New York: Holt, Rhinehart \& Winston, 1972, pp. 35-71.

Hymes, Dell. "Ways of Speaking.” Explorations in the Ethnography of Speaking, edited by Bauman, Richard and Sherzer, Joel. Cambridge: Cambridge University Press, 1974, pp. 433-451. 
Johnsen, Ole Ringdal. “He‘s My Sister! Gender Inversion in Gay Men‘s Speech.” Språk, kön och kultur, edited by Nordenstam, K. and Norén, K. Göteborg, 2001, pp. 133-141.

Johnsen, Ole Ringdal. “'He’s a Big Old Girl!’ Negotiation by Gender Inversion in Gay Men’s Speech.” Journal of Homosexuality, vol. 54, no.1-2, 2008, pp. 150-168.

Kozloff, Sarah. Overhearing Film Dialogue. Berkeley, CA: University of California Press, 2000.

Kulick, Don. “Gay and Lesbian Language.”Annual Review of Anthropology, vol. 29, 2000, pp. 243-285.

Labov, William. Sociolinguistic Patterns. Philadelphia: University of Philadelphia Press, 1972.

Livia, Anna. Pronoun Envy. Literary Uses of Linguistic Gender. Oxford: OUP, 2001.

Livia, Anna. “The Future of Queer Linguistics.” Language and Sexuality: Contesting Meaning in Theory and Practice, edited by Campbell-Kibler et al. Stanford, Calif: CSLI Publications, 2002, pp.87-98.

Lyons, John. New Horizons in Linguistics, London: Penguin, 1970.

McCraney, Tarell Alvin. Wig Out! Faber \& Faber, 2014.

McEnery, Tony and Hardie, Andrew. Corpus linguistics: Method, theory and practice. Cambridge: Cambridge University Press, 2012.

Metzger, Megan. M. That's Ru-volting! how reality TV reimagines perceptions of American success. College of Liberal Arts \& Social Sciences Theses and Dissertations, 2016.

Moncrieff, Michael and Lienard, Pierre. "A Natural History of the Drag Queen Phenomenon.” Evolutionary Psychology, vol. 15, no.2, 2017, pp. 1-14.

Moore, Ramey. "Everything Else is Drag: Linguistic Drag and Gender Parody on RuPaul's Drag Race.” Journal of Research in Gender Studies, vol. 3, no. 2, 2013, pp. 15-26.

Motschenbacher, Heiko. "Taking Queer Linguistics Further: Sociolinguistics and Critical Heteronormativity Research.” International Journal of the Sociology of Language, vol. 212, pp.149-179.

Motschenbacher, Heiko and Stegu, Martin. “Queer Linguistic Approaches to Discourse.” Discourse \& Society, vol. 24, no. 5, 2013, pp. 519-535.

Nagel, Joane. Race, Ethnicity, and Sexuality: Intimate Intersections, Forbidden Frontiers. New York: Oxford University Press, 2003.

Oostrik, Sven. Doing Drag: From Subordinate Queers to Fabulous Queens Drag as an Empowerment Strategy for Gay Men (thesis), 2014.

Parker, Ian. Discourse Dynamics. Critical analysis for social and individual psychology. London, New York: Routledge, 2014.

RuPaul, Charles. Workin' It!: RuPaul's Guide to Life, Liberty and the Pursuit of Style, Harper Collins, 2010.

Saussure, Ferdinand de. Course in General Linguistics. Bally C., Sechehaye, A. (eds), trans. R. Harris, London: Duckworth, 1966.

Schacht, Steven P. and Lisa, Underwood. "The Absolutely Fabulous but Flawlessly Customary World of Female Impersonators.” Journal of Homosexuality, vol. 46, no. 3-4, 2004, pp. 1-17. 
Sherzer, Joel. “The Ethnography of Speaking: A Critical Appraisal.” Linguistics and Anthropology, edited by Saville-Troike, Muriel. Washington DC: Georgetown University Press, 1977.

Sokalska-Bennett, Aleksandra. "Imagine a boy who is adopted by a Pair of Lesbians (Poor Little Sod).” Journal of Language and Sexuality, vol. 6, no.1, 2017, pp. 61-89.

Swann, Joan et al. A Dictionary of Sociolinguistics. Edinburgh: Edinburgh University Press, 2004.

Tognini-Bonelli, Elena. Corpus Linguistics at Work. Amsterdam: John Benjamins, 2001. Warner, Michael. “Introduction: Fear of a Queer Planet.” Social Text, vol. 29, 1991: pp. 3-17.

Way, Christopher. We Are Family! I've got my drag sister with me: an examination of the relationship between visual media and drag family structure. Lake Forest College. (thesis), 2014.

West, Candace and Zimmerman, Don. “Doing Gender.” Gender and Society, vol. 1, no. 2, pp. 125-151.

\section{BIONOTE}

Davide PASSA is a PhD student in Studies in English literatures, cultures, language, and translation (Language and Translation Studies) at Sapienza University of Rome (in co-tutelle with University of Silesia in Katowice; tutors: Irene Ranzato, Adam Wojtaszek), where he has also been nominated Graduate Teaching Assistant in L-LIN/12 English language and translation. He has mainly worked on non-standard English varieties and their representation and translation in audiovisual and literary products. He is a member of AIA (Associazione Italiana di Anglistica), EST (European Society for Translation Studies) and IATIS (International Association for Translation and Intercultural Studies), as well as part of the Editorial Staff of the class-A journal Status Quaestionis. He has published articles on the fictional use of sociolects and their rendering in translation, with particular attention to fictional gayspeak and drag lingo. His $\mathrm{PhD}$ thesis focuses on the linguistic characterisation of fictional gay men in twentyfirst century British drama. His main research interests are Sociolinguistics, (Audiovisual) Translation Studies, language and sexuality studies, corpus linguistics. He teaches English language and culture in secondary schools.

E-mail: davide.passa@uniroma1.it 